\title{
Dynamic kine magnetic resonance imaging in whiplash patients and in age- and sex-matched controls
}

\author{
Karl-August Lindgren $\mathrm{MD} \mathrm{PhD}^{1}$, Jyrki A Kettunen $\mathrm{PT} \mathrm{PhD}^{2}$, Markku Paatelma PT ${ }^{3}$, Raija HM Mikkonen MD PhD ${ }^{4}$
}

\begin{abstract}
K-A Lindgren, JA Kettunen, M Paatelma, RHM Mikkonen. Dynamic kine magnetic resonance imaging in whiplash patients and in age- and sex-matched controls. Pain Res Manage 2009;14(6):427432.

The multitude of symptoms following a whiplash injury has given rise to much discussion because of the lack of objective radiological findings. The ligaments that stabilize the upper cervical spine can be injured. Dynamic kine magnetic resonance imaging (dMRI) may reveal the pathological motion patterns caused by injury to these ligaments. To compare the findings and motion patterns in the upper cervical spine, 25 whiplash trauma patients with longstanding pain, limb symptoms and loss of balance indicating a problem at the level of $\mathrm{CO}-\mathrm{C} 2$, as well as matched healthy controls were imaged using dMRI. Imaging was performed with an Intera $1.5 \mathrm{~T}$ (Philips Healthcare, USA) magnet. A physiotherapist performed the bending and rotation of the upper cervical spine for the subjects to ensure that the movements were limited to the $\mathrm{CO}-\mathrm{C} 2$ level. An oblique coronal $\mathrm{T} 2$ - and proton density-weighted sequence and a balanced fast field echo axial sequence were used. The movements between $\mathrm{CO}-\mathrm{C} 2$ and the signal from the alar ligaments were analyzed. Contact of the transverse ligament and the medulla in rotation was seen in two patients. The signal from the alar ligaments was abnormal in $92 \%$ of the patients and in $24 \%$ of the control subjects $(\mathrm{P}<0.0001)$. Abnormal movements at the level of $\mathrm{C} 1-\mathrm{C} 2$ were more common in patients than in controls $(56 \%$ versus $20 \%$, $\mathrm{P}=0.028$ ). Whiplash patients with longstanding symptoms had both more abnormal signals from the alar ligaments and more abnormal movements on $\mathrm{dMRI}$ at the $\mathrm{CO}-\mathrm{C} 2$ level than controls.
\end{abstract}

Key Words: Alar ligament; Kine; MR imaging; Occipitoatlantoaxial complex; Whiplash injury

\author{
La ciné-imagerie par résonance magnétique \\ dynamique chez des patients ayant subi un \\ coup de fouet cervical et chez des sujets \\ témoins appariés selon l'âge et le sexe
}

La multitude de symptômes après un coup de fouet cervical a suscité de nombreuses discussions en raison de l'absence de résultats radiologiques objectifs. Les ligaments qui peuvent stabiliser la colonne cervicale supérieure peuvent subir un traumatisme. La ciné-imagerie par résonance magnétique dynamique (IRMd) peut révéler le profil de mouvements pathologiques provoqué par le traumatisme de ces ligaments. Pour comparer les observations et le profil de mouvements de la colonne cervicale supérieure, 25 patients ayant subi un traumatisme par coup de fouet cervical ayant des douleurs, des symptômes dans les membres et une perte d'équilibre de longue date et faisant état d'un problème aux vertèbres C0-C2, de même que des sujets témoins appariés en santé, ont subi une IRMd. On a procédé à cette imagerie au moyen d'un aimant Intera $1.5 \mathrm{~T}$ (Philips Healthcare, États-Unis). Un physiothérapeute a procédé au fléchissement et à la rotation de la colonne cervicale supérieure chez les sujets pour s'assurer que les mouvements se limitaient aux vertèbres C0-C2. On a utilisé une image coronaire oblique par séquence pondérée T2 et de densité des protons (T2pd) et par séquence axiale équlibrée écho de gradient (FFE). On a analysé le mouvement entre les vertèbres C0-C2 et le signal des ligaments auxiliaires. On a observé un contact entre le ligament transverse et la région médullaire en rotation chez deux patients. Le signal des ligaments auxiliaires était anormal chez $92 \%$ des patients et chez $24 \%$ des sujets témoins $(\mathrm{P}<0,0001)$. Les mouvements anormaux au niveau des vertèbres $\mathrm{C} 0$-C2 étaient plus courants chez les patients que chez les sujets témoins ( $56 \%$ par rapport à $20 \%, \mathrm{P}=0,028)$. Les patients ayant subi un coup de fouet cervical qui avaient des symptômes de longue date présentaient à la fois plus de signaux anormaux des ligaments auxiliaires et plus de mouvements anormaux au niveau des vertèbres C0-C2 à l'IRMd que les sujets témoins.

Whiplash injuries affecting the upper cervical spine may cause upper cervical syndrome (8), which is characterized by such symptoms as balance disturbances, dizziness, visual problems and jaw pain.

In handling spine trauma, ensuring neck stability is the key objective. At the craniocervical junction, the alar and transverse ligaments provide much of the stability of the healthy spine. The alar ligaments restrain rotation of the upper cervical spine. Abnormal movement patterns in these segments are hypothesized to be caused by an injury to the alar ligaments (9). It has been demonstrated that the alar ligaments can bear an average load of $270 \mathrm{~N}$, whereas the transverse ligaments tolerate an average of $330 \mathrm{~N}$ of axial load (9). The alar ligaments may be irreversibly overstretched or even ruptured in unexpected rear-end collisions (6). 
TABLE 1

Characteristics, work ability and symptoms of participants

\begin{tabular}{lccr}
\hline Characteristics & Patients & Controls & P \\
\hline Sex, females/males, $\mathrm{n}$ & $15 / 10$ & $15 / 10$ & \\
Age, years & $42.3 \pm 6.7$ & $41.8 \pm 6.7$ & 0.801 \\
Work ability, VAS $(0-10 \mathrm{~cm})$ & $3.1 \pm 3.0$ & $9.7 \pm 0.6$ & $<0.001$ \\
Neck Disability Index & $57.9 \pm 10.7$ & $3.9 \pm 3.9$ & $<0.001$ \\
Neck pain at the time of imaging, & $66.4 \pm 21.4$ & $1.5 \pm 2.5$ & $<0.001$ \\
VAS (0-100 mm) & & & \\
\hline
\end{tabular}

Data presented as mean $\pm S D$ unless otherwise indicated. VAS Visual analogue scale

Magnetic resonance imaging (MRI) has been used in several studies to examine the alar ligaments. Krakenes et al (10) showed that the major ligamentous structures in the craniovertebral junction can be detected and characterized by the use of high-resolution proton density-weighted magnetic resonance sequences. Excellent assessment of ligaments and membranes was possible, and detailed information was obtained. Furthermore, Krakenes et al (11) showed that the alar ligaments are vulnerable to whiplash injury and that the severity of the lesions can be graded using high-resolution MRI.

Kim et al (12) stated that a reliable assessment of the alar ligaments can be achieved with MRI. They also stated that a functional study may be a valuable imaging modality in the evaluation of alar ligament failure. Functional MRI (fMRI) was used in a recent case report (13). The protocol of fMRI for whiplash patients was presented by Volle in 2000 (14). Vantaan Magneetti Ltd (Vantaa, Finland) has performed MRI in more than 200 whiplash patients using this method. Usually, clinical patient studies include the whole cervical spinal column, but our interest was in the $\mathrm{CO}-\mathrm{C} 2$ area because of suspicion of ligament failure in this area. Because the term 'functional MRI' is often used in neuroscience to study metabolic functions, we used the term 'dynamic kine MRI' (dMRI) in the present study to avoid confusion.

Overall, the method of Volle (14) has not been widely used. One reason for this may be that there are no data on differences in motion patterns between WAD patients and healthy subjects. Therefore, we conducted a study to investigate the possible differences in findings and motion patterns of the upper cervical spine in whiplash trauma patients and their age- and sex-matched healthy controls using dMRI. Specifically, we analyzed the movement between $\mathrm{C} 1$ and $\mathrm{C} 2$ during side bending and instability of the $\mathrm{CO}$ and $\mathrm{C} 1$ joints, as well as the existence of contact between the transverse ligament and the medulla during rotation of $\mathrm{CO}-\mathrm{C} 2$.

\section{Subjects}

\section{METHODS}

Thirty consecutive whiplash trauma patients were identified, who had been admitted to the ORTON Rehabilitation Centre (Helsinki, Finland) for physiatric consultation because of their severe chronic symptoms. The patients had persistent symptoms such as neck pain and/or headache, upper limb and even lower limb symptoms, loss of balance, and some numbness of the tongue, which is a cardinal feature of the neck-tongue syndrome (15). All of these symptoms could be explained by a problem at the $\mathrm{C} 0$ to $\mathrm{C} 2$ level (16). The mean ( \pm SD) time between injury and dMRI examination in patients was $7.8 \pm 7.5$ years.
Thirty healthy volunteers matched for age and sex were enrolled in the present study. They had no history of neck sprain, trauma to the head or cervical spine, or inflammatory diseases such as rheumatoid arthritis.

Both patients and controls gave their written informed consent. In five patients, images could not be obtained; therefore, their matched control subjects were also excluded. The final study group comprised 10 male patients (mean age 41.2 years) and 15 female patients (mean age 43.1 years), as well as 10 male controls (mean age 41.6 years) and 15 female controls (mean age 42.0 years). The characteristics of the study subjects are presented in Table 1.

\section{Clinical evaluation}

The self-reported health status among patients before injury was questioned $(1=$ very good, $2=$ good, $3=$ moderate, $4=$ bad $)$. Retrospectively, $96 \%$ of the patients rated their health status as very good or good before their injury.

Each subject's neck pain and disability was evaluated with the Neck Disability Index (NDI) (17) and with a $100 \mathrm{~mm}$ visual analogue scale (VAS) just before the dMRI examination. The NDI consists of 10 items addressing functional activities (personal care, lifting, reading, work, driving, sleeping, recreational activities, pain intensity, concentration and headache). For each item there are six potential responses, each describing a greater degree of disability (no disability $=0$, to total disability $=5$ ). An overal NDI score out of 100 is calculated by adding the scores for each item and multiplying by two. Current work ability was evaluated with a $10 \mathrm{~cm}$ VAS $(0=$ unable to work and $10=$ fully fit for work).

\section{dMRI}

Imaging was performed with an Intera $1.5 \mathrm{~T}$ magnet (Philips Healthcare, USA). The participant was placed in the supine position, and a Flex L coil (Philips Healthcare) was attached to both sides of the head with stickers. The physiotherapist (MP) performed the bending and rotation of the participant's head to ensure that the movements were limited to the level of $\mathrm{CO}-\mathrm{C} 2$. He maintained the required posture control position throughout the imaging time for both patients and controls.

Maximal rotation to the left and right was performed by fixing the C2 vertebra (Figure 1) (18). A kine-balanced fast field echo (FFE) sequence was performed in seven different positions. The following parameters were used: field of view (FOV) $375 \mathrm{~mm}^{2}$, matrix $224 \times 224$, slice thickness $4.0 \mathrm{~mm}$, gap $0.0 \mathrm{~mm}$, flip angle (FA) $60^{\circ}$, repetition time (TR) $4.6 \mathrm{~ms}$, echo time (TE) $2.3 \mathrm{~ms}$ and a shim volume.

Maximal side bending to the left and right was performed by supporting the opposite side of the neck (Figure 2) (19). A T2and proton density-weighted oblique coronal sequence was placed parallel to the anterior surface of $\mathrm{C} 2$. The following parameters were used: FOV $200 \mathrm{~mm}^{2}$, matrix $256 \times 256$, slice thickness $2.0 \mathrm{~mm}$, gap $0.0 \mathrm{~mm}$, FA $90^{\circ}$, TR $3025 \mathrm{~ms}$ and TE $11 / 120$ ms. A balanced FFE sequence was performed in the neutral position. The following parameters were used: FOV $375 \mathrm{~mm}^{2}$, matrix $224 \times 224$, slice thickness $4.0 \mathrm{~mm}$, gap $0.0 \mathrm{~mm}$, FA $60^{\circ}$, TR $4.6 \mathrm{~ms}$ and TE $2.3 \mathrm{~ms}$. All images were analyzed by the same experienced radiologist (RM) on an Easy Vision workstation (Philips Healthcare).

The analysis of the dMRI findings was performed blinded. All of the coronal images were reconstructed on the workstation 

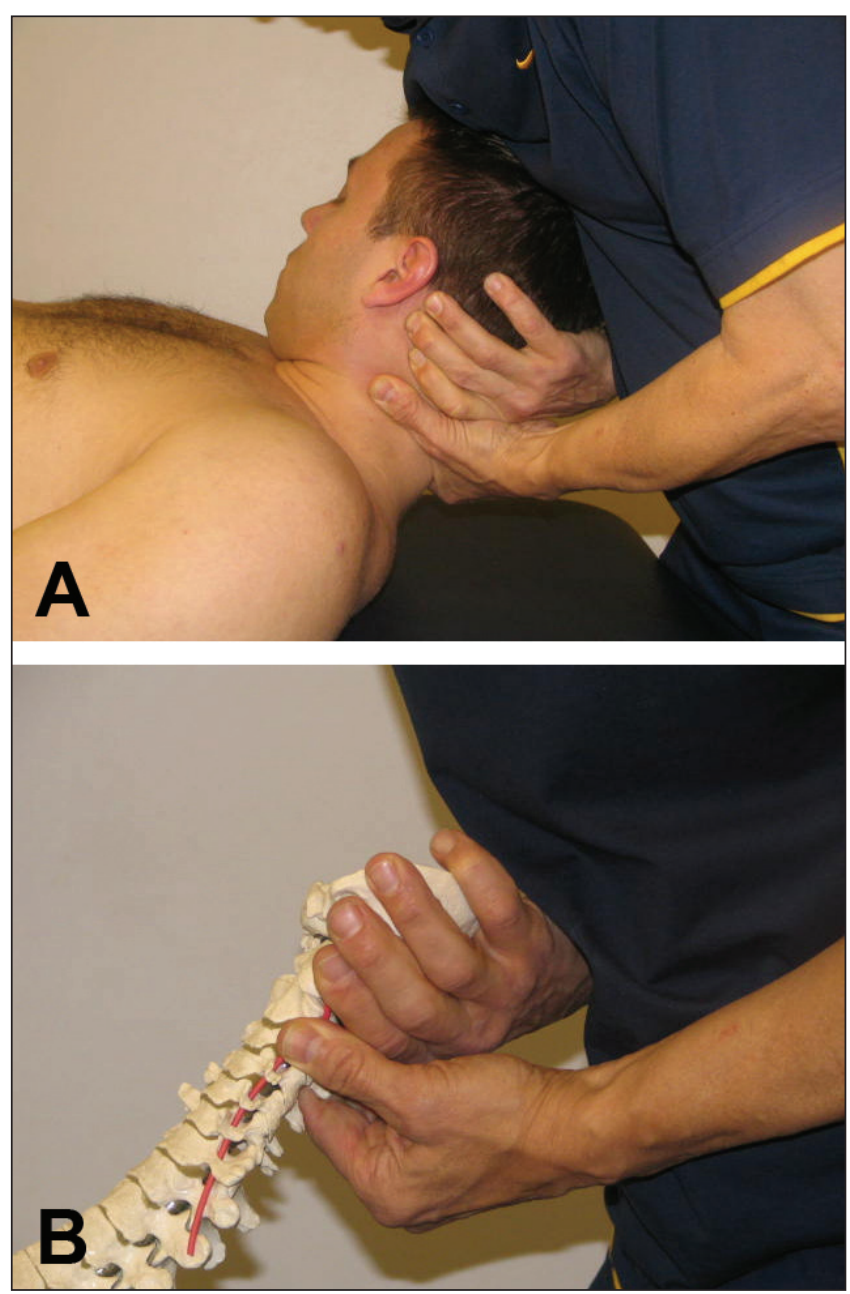

Figure 1) A Rotation of the atlas on axis by fixing the C2 vertebra. B The same technique demonstrated on a skeleton

before the analysis so that the $\mathrm{C} 2$ vertebra was in the coronal plane.

The signal from the alar ligaments was analyzed from the oblique coronal T2 images. The signal was classified as $0-$ the alar ligament could not be seen (nonvisualized ligament) (Figure 3); 1 - the alar ligament was partly seen (Figure 4); or 2 - the whole alar ligament could be seen (normal) (Figure 5).

The classification of the signals from the alar ligaments was later dichotomized and analyzed as follows: 0 - the whole alar ligament (right and left) could be seen; or 1 - either the left or the right alar ligament was partly seen or could not be seen.

The interval between the dens and C1 was measured using proton-weighted images. The movement of the dens in relation to the atlas when side bending the cervical spine was classified as 0 - dens movement in the physiological direction (Figure 6); 1 - dens movement in an abnormal direction; or 2 - no movement (Figure 7). When side bending the cervical spine to the left, the physiological direction of the movement of the dens is to the right and vice versa.

The classification of the movement of the dens was later dichotomized and analyzed as follows: 0 - the movement of the dens is physiological both to the left and to the right; or 1 - no movement or movement in an abnormal direction during at least one of the two side bendings.
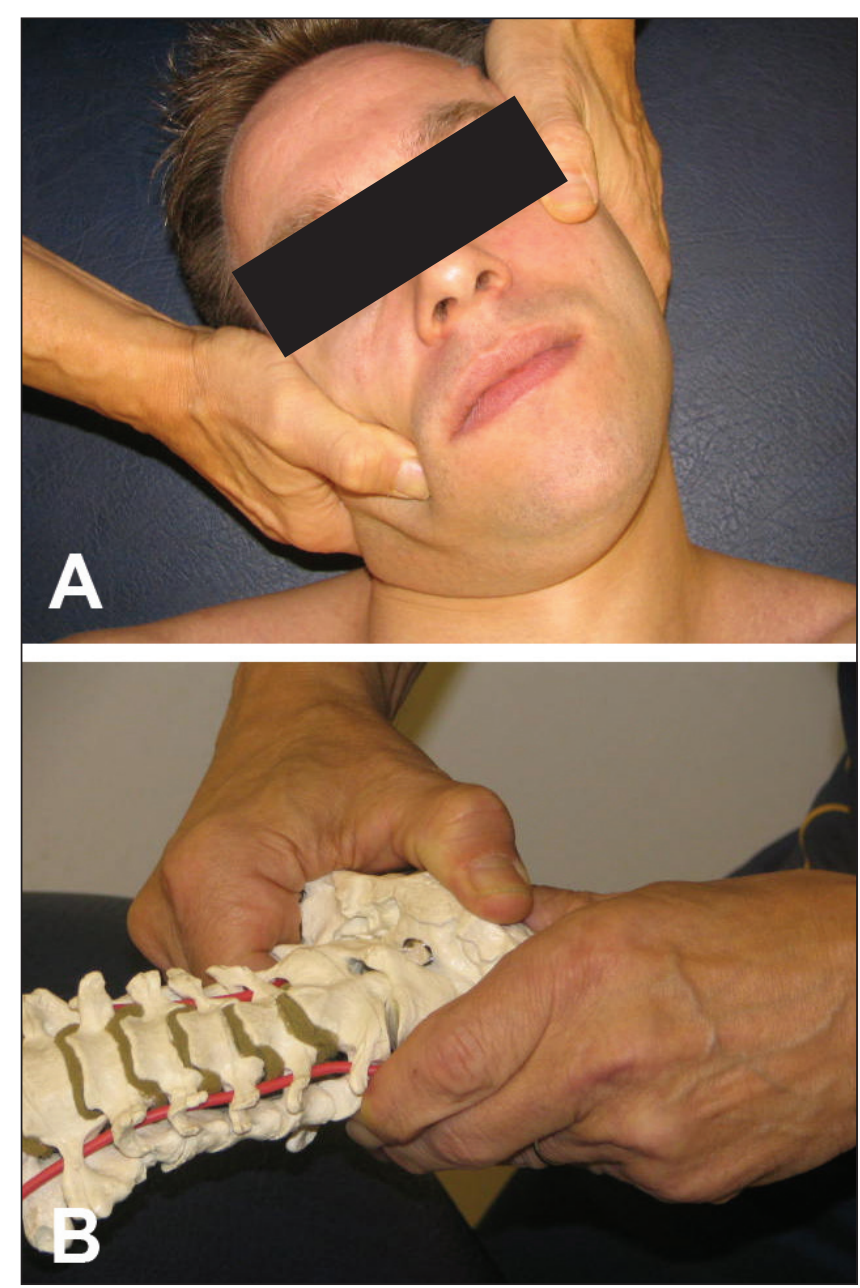

Figure 2) A Upper cervical side bending performed by supporting the opposite side of the neck. B The same technique demonstrated on a skeleton

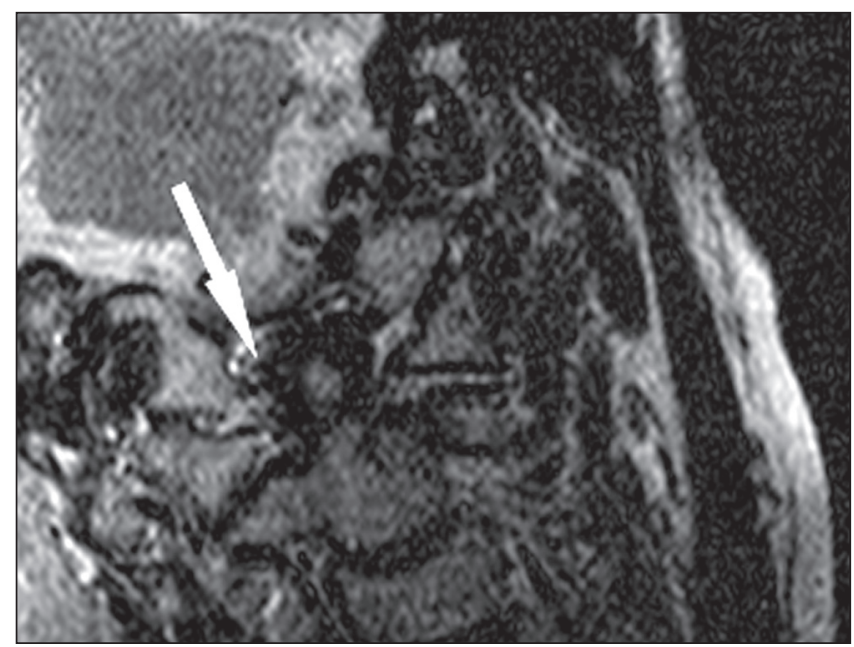

Figure 3) Totally ruptured alar ligament (arrow)

The possible contact between the transverse ligament and the medulla during maximal rotation (Figures $8 \mathrm{~A}$ to $8 \mathrm{G}$ ) was analyzed from the balanced FFE images.

The ethical committee of the Hospital District of Helsinki and Uusimaa (Finland) and the review board of the ORTON 


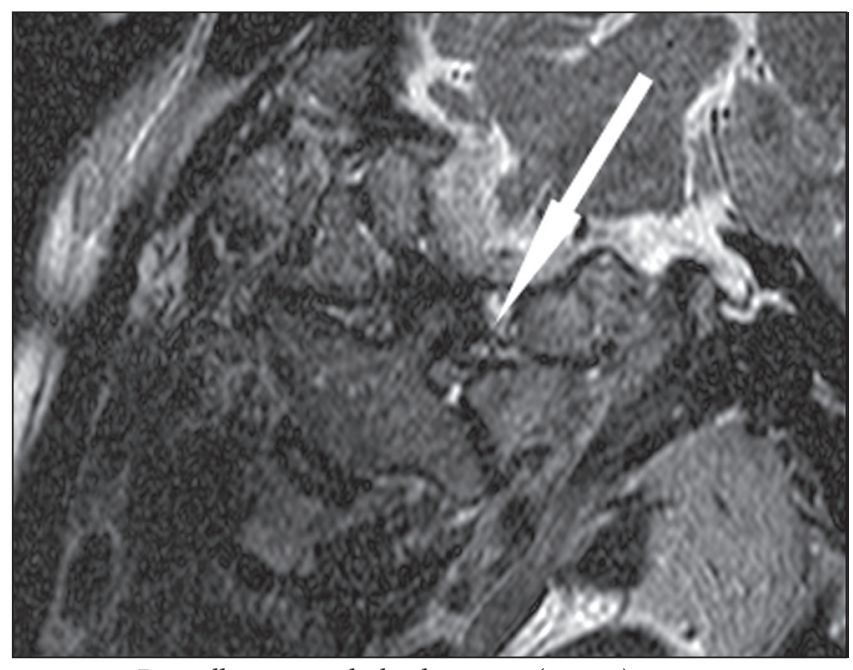

Figure 4) Partially ruptured alar ligament (arrow)

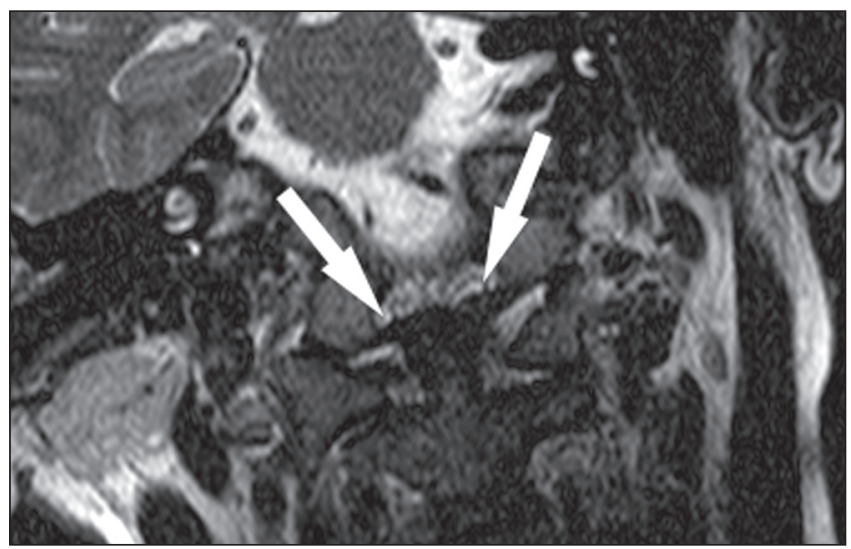

Figure 5) Normal alar ligaments (arrows)

Orthopaedic Hospital (Helsinki, Finland) approved the study protocol.

\section{Data analysis}

The statistical analysis was performed with SPSS version 15.0 (SPSS Inc, USA). Student's $t$ test and the $\chi^{2}$ test were used to compare group differences.

\section{RESULTS}

As expected, the patients reported more neck pain and disability than the controls according to the NDI and VAS, and the mean current work ability score was higher in controls than in patients (Table 1).

The signal from the alar ligaments was abnormal in 23 (92\%) of the patients and in six (24\%) of the control subjects $(\mathrm{P}<0.0001$ between groups). Only two $(8 \%)$ of the patients had a normal signal, and none of the six controls with abnormal signals from the alar ligaments had a nonvisualized ligament.

Fifty-six per cent $(n=14)$ of the patients and $20 \%(n=5)$ of the control subjects had abnormal movement of the dens ( $\mathrm{P}=0.028$ for group differences). However, of these 19 subjects (patients and controls combined) with an abnormality, only one patient had movement in an abnormal direction and in all others $(\mathrm{n}=18)$, the abnormality was 'no movement of dens'.
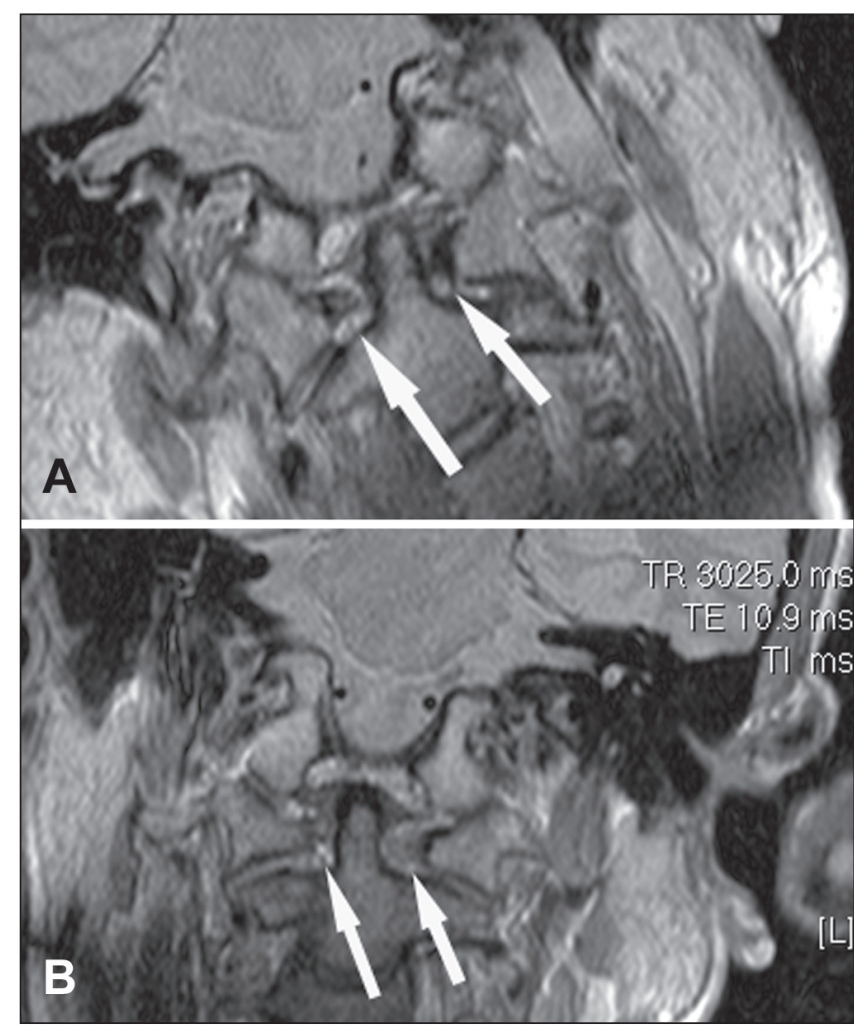

Figure 6) A Normal movement of the dens during side bending to the right (arrows). B Normal movement of the dens during side bending to the left (arrows)

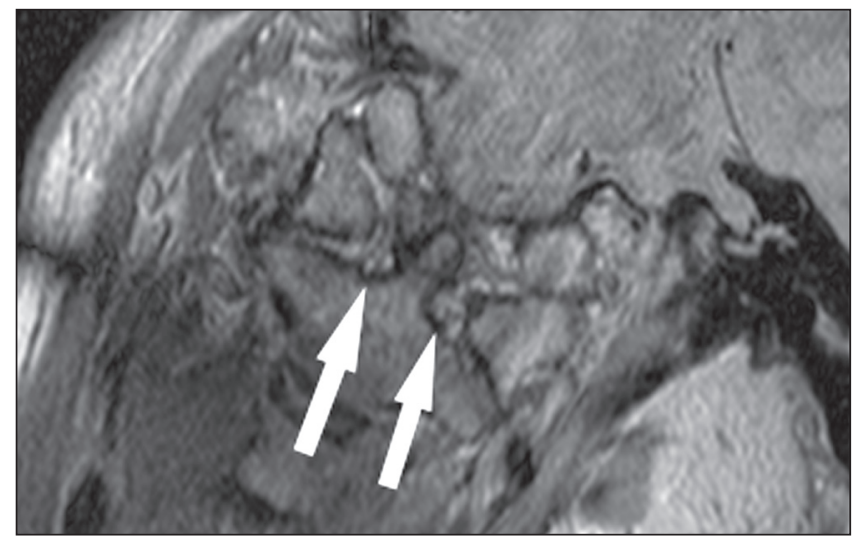

Figure 7) No movement of the dens during side bending (arrows)

The C0-C1 level was analyzed during side bending. In the present study, $\mathrm{CO}-\mathrm{C} 1$ was widened on either one or both sides in seven patients and in one control subject, who was a 50-year-old man. In these eight individuals, the width of the joint was $1.5 \mathrm{~mm}$ to $2.9 \mathrm{~mm}$. Widening of the $\mathrm{C} 0-\mathrm{C} 1$ joint indicates an unstable joint.

Contact between the transverse ligament and the medulla could be seen in two patients, but in none of the controls. These two patients had only partly visible alar ligaments. During rotation, contact with the medulla appeared on the same side as the partly visualized alar ligament.

Among the controls, all of the alar ligaments were visualized. In one patient, one alar ligament was not visualized. 


\section{DISCUSSION}

The craniocervical junction is a potential site of injury in whiplash patients (20). In a functional computed tomography study published in 1987, Dvorak and Panjabi (5) suspected that an abnormal movement between $\mathrm{C} 1$ and $\mathrm{C} 2$ strongly suggested alar ligament insufficiency. Our study found that whiplash patients with longstanding symptoms had more abnormal signals from the alar ligaments and movement disturbances at the CO-C2 level in the dMRI.

Some authors claim that only some of the alar ligaments can be visualized, and the reliability of assessing signal abnormality is poor $(21,22)$. One study in healthy individuals showed extensive anatomical variations, and the authors concluded that changes in these ligaments would have little clinical relevance (21). In that study, the alar ligaments were detected on the left side in $84 \%$ and on the right side in $76 \%$ of the subjects, respectively. In our study, we were able to detect the alar ligaments in all control subjects and in all other patients, except in one. One explanation for this difference in detecting the alar ligaments may be that Pfirrmann et al (21) used $4 \mathrm{~mm}$ slices. They gave no information about the gap they used in their study. A gap of more than $0 \mathrm{~mm}$ could possibly explain their low alar ligament detection rate. We used a slice thickness of $2 \mathrm{~mm}$ with a gap of $0.0 \mathrm{~mm}$. Roy et al (22) questioned the reliability of assessing signal abnormality. However, they used a $0.5 \mathrm{~T}$ magnetic resonance scanner with a vertical open bore, which has low image quality. Krakenes et al (11) stressed the importance of a slice thickness of $2 \mathrm{~mm}$. Kim et al (12) believe that a reliable assessment of the integrity of the alar ligaments can be achieved.

Functional imaging of the cervical spine is a traditional method in radiology. Radiologists and clinicians are familiar with the use of extension and flexion images in imaging instability of the cervical spine and the atlantoaxial subluxation of the $\mathrm{C} 1-\mathrm{C} 2$ complex in patients with rheumatoid arthritis. The information obtained from $x$-rays is limited. While the bony structures can easily be seen in $\mathrm{x}$-ray images, the soft tissues are not visible. The alar ligaments can be visualized using MRI. The benefit of side bending the cervical spine is illustrated in patients with normal movement because the opposite alar ligament can be seen as it straightens, and possible changes in the signal can be seen more effectively.

Contact between the transverse ligament and the medulla can only be seen during rotation using fMRI (14). Among patients with rheumatoid arthritis, contact with the spinal cord can be seen during extension and flexion if an atlantoaxial subluxation exists (23). The normal movement between $\mathrm{C} 1$ and C2 is well documented (24). Because of the lack of a disc and the horizontal nature of the facet joints, the stability of the atlantoaxial complex depends mainly on the ligaments and muscles. The most important function of the alar ligaments is to limit axial rotation of the head. Of the rotation of the cervical spine, $55 \%$ occurs at the atlantoaxial joint, $5 \%$ in the atlanto-occipital joint and $40 \%$ is accounted for by the remainder of the cervical spine (25).

The mean NDI score was very high among the patients, indicating severe symptoms. Previous authors have stated that symptoms and complaints among WAD patients can be linked with structural abnormalities of the ligaments and membranes in the upper cervical spine, particularly the alar ligaments (26).
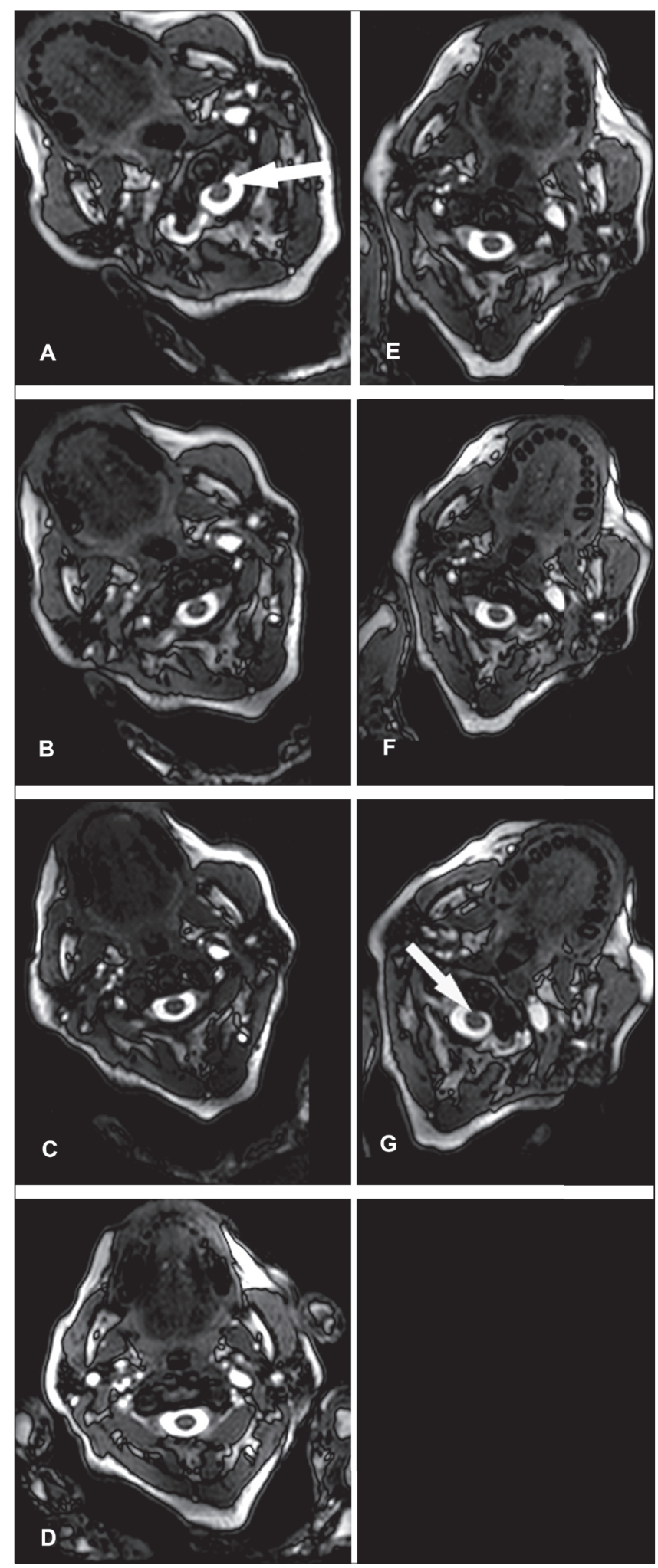

Figure 8) A to $\mathrm{G}$ Functional myelopathy during rotation. Arrows indicate contact between the transverse ligament and the medulla during rotation, which is abnormal

When assessing MRI findings, one has to correlate findings to the symptoms and the clinical status. It has also been shown that asymptomatic individuals can have abnormal MRI findings (27). Only one of our patients had physiological movement of the 
dens, and a normal signal from the alar ligaments. However, some of our control subjects also had at least one abnormal finding. The importance of matching MRI findings with clinical signs and symptoms was stressed almost two decades previously (28).

Conventional computed tomography and conventional MRI are not appropriate tests with which to rule out pathology. Static imaging does not reveal movement abnormalities. The pursuit of pathology in chronic WAD requires specialized and sophisticated methods (16). fMRI seems very appropriate for patients with signs of high cervical lesions (16). A recent study reported that abnormal findings on fMRI could be verified in almost all surgically treated patients (29). A case report described patients who had alar ligament ruptures, visualized by fMRI, and who underwent a surgical stabilization of the $\mathrm{C} 0-\mathrm{C} 2$ complex, which improved their medical condition (30). A long-term follow-up study after occipitocervical fixation, $22 \%$ of whom had experienced trauma, found that all patients with successful fixation had pain resolution (31). We found that many whiplash patients with persisting disabilities had alar ligament abnormalities, and

\section{REFERENCES}

1. Spitzer WO, Skovron MI, Salmi LR, et al. Scientific monograph of the Quebec Task Force on Whiplash Associated Disorders: Redefining whiplash and its management. Spine 1995;20:1S-73S.

2. Barnsley L, Lord S, Bogduk N. Whiplash injury. Pain 1994;58:283-307.

3. Miettinen T, Leino E, Airaksinen O, Lindgren K-A. Whiplash injuries in Finland: The situation three years later. Eur Spine J 2004;13:415-8

4. Barnsley L, Lord SM, Wallis BJ, Bogduk N. The prevalence of chronic cervical zygapophysial joint pain after whiplash. Spine 1995;20:20-5

5. Dvorak J, Panjabi MM. Functional anatomy of the alar ligaments. Spine 1987;12:183-91.

6. Saldinger P, Dvorak J, Rahn BA, Perren SM. Histology of the alar and transverse ligament. Spine 1990;15:257-61.

7. Willauschus WG, Kladny B, Dreyer WF, Gluckert K, Arnold H, Scheithauer R. Lesions of the alar ligaments. In vivo and in vitro studies with magnetic resonance imaging. Spine 1995;20:2493-8.

8. Radanov BP, Dvorák J, Valach L. Cognitive deficits in patients after soft tissue injury of the cervical spine. Spine 1992;17:127-31.

9. Dvorak J, Schneider E, Saldinger P, Rahn B. Biomechanics of the craniocervical region: The alar and transverse ligaments. J Orthop Res 1988;6:452-61.

10. Krakenes J, Kaale BR, Rovvik J, Gilhus NE. MRI assessment of normal ligamentous structures in the craniovertebral junction. Neuroradiol 2001;43:1089-97.

11. Krakenes J, Kaale BR, Moen G, Nordli H, Gilhus NE, Rorvik J. MRI assessment of the alar ligaments in the late stage of whiplash injury - a study of structural abnormalities and observer agreement. Neuroradiol 2002;44:617-24.

12. Kim H-J, Jun B-Y, Kim WH, Cho YK, Lim MK, Suh CH. MR imaging at the alar ligament: Morphological changes during axial rotation of the head in asymptomatic young adults. Skeletal Radiol 2002;31:637-42.

13. Johansson BH. Whiplash injuries can be visible by functional magnetic resonance imaging. Pain Res Manage 2006;11:197-9.

14. Volle E. Functional magnetic resonance imaging - video diagnosis of soft-tissue trauma to the craniocervical joints and ligaments. Int Tinnitus J 2000;6:134-9

15. Lance JW, Anthony M. Neck-tongue syndrome on sudden turning of the head. J Neurol Neurosurg Psychiatry 1980;43:97-101.

16. Bogduk N. Whiplash can have lesions. Pain Res Manage 2006;11:155.

17. Vernon H, Mior S. The Neck Disability Index: A study of reliability and validity. J Manipulative Physiol Ther 1991;14:409-15. disturbed function of the $\mathrm{C} 0-\mathrm{C} 2$ complex. The question of whether these patients would benefit from stabilization of the occipitocervical junction requires further investigation.

Abnormalities in proprioception and in the upper neural coordination centres produce symptoms similar to those seen in our whiplash patients. There is a need for further investigations to examine whether damage to the upper cervical spine and ligaments could contribute to such symptoms.

\section{CONCLUSIONS}

The present study is, to our knowledge, the first comparative MRI study to use dMRI among whiplash patients and controls. The results showed that whiplash patients with longstanding symptoms had both more abnormal signals from the alar ligaments and more abnormal movements in the dMRI at the C0-C2 level than controls.

ACKNOWLEDGEMENTS: This study was supported by the research fund administered by the Ministry of Social Affairs and Health (Finland).
18. Cattrysse E, Baeyens JP, Clarys JP, Van Roy P. Manual fixation versus locking during upper cervical segmental mobilization. Part 2: An in vitro three-dimensional arthrokinematic analysis of manual axial rotation and lateral bending mobilization of the atlanto-axial joint. Man Ther 2007;12:353-62.

19. Cattrysse E, Baeyens JP, Clarys JP, Van Roy P. Manual fixation versus locking during upper cervical segmental mobilization. Part 1: An in vitro three-dimensional arthrokinematic analysis of manual flexion-extension mobilization of the atlanto-occipital joint. Man Ther 2007;12:342-52.

20. Penning L. Hypertranslation de kopfes nach hinten: Teil des scheuderverletzung mechanismus der HWS? Orthopade 1994:23:268-74.

21. Pfirmann CW, Binkert CA, Zanetti M, Boos N, Hodler J. MR morphology of alar ligaments and occipitoatlanto-axial joints: A study in 50 asymptomatic subjects. Radiol 2001;218:133-7.

22. Roy S, Hol PK, Laerum LT, Tillung T. Pitfalls of magnetic resonance imaging of alar ligament. Neuroradiol 2004;46:392-8.

23. Gupta V, Khandelwal N, Mathuria SN, Singh P, Pathak A, Suri S. Dynamic magnetic resonance imaging evaluation of craniovertebral junction abnormalities. J Comput Assist Tomogr 2007;31:354-9.

24. Panjabi M, Dvorak J, Crisco J, Oda T, Hilbrand A, Grob D. Flexion, extension and lateral bending of the upper cervical spine in response to alar ligament transactions. J Spinal Disord 1991;4:157-67.

25. White AA, Panjabi MB. Clinical Biomechanics of the Spine, 2nd edn. Philadelphia: JB Lippincott, 1990.

26. Kaale BR, Krakenes J, Albrektsen G, Wester K. Whiplashassociated disorders impairment rating: Neck disability index score according to severity of MRI findings of ligaments and membranes in the upper cervical spine. J Neurotrauma 2005;22:466-75.

27. Siivola SM, Levoska S, Tervonen O, Ilkko E, Vanharanta H, Keinänen-Kiukaanniemi S. MRI changes of cervical spine in asymptomatic and symptomatic young adults. Eur Spine J 2002:4:358-63.

28. Boden SD, McCowin PR, Davis DO, Dina TS, Mark AS, Wiesel S. Abnormal magnetic-resonance scans of the cervical spine in asymptomatic subjects. A prospective investigation. J Bone Joint Surg Am 1990;72:1178-84.

29. Johansson B, Arvidsson I. The correlation between surgical and MRI findings after trauma to the upper cervical spine. J Whiplash Relat Disord 2006;5:37-42.

30. Johansson $\mathrm{BH}$. Whiplash injuries can be visible by functional magnetic resonance imaging. Pain Res Manage 2006;11:197-9.

31. Deutsch H, Haid RW Jr, Rodts GE Jr, Mummaneni PV. Occipitocervical fixation: Long-term results. Spine 2005;30:530-5. 


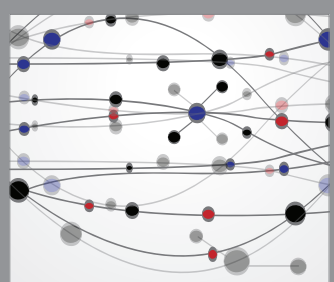

The Scientific World Journal
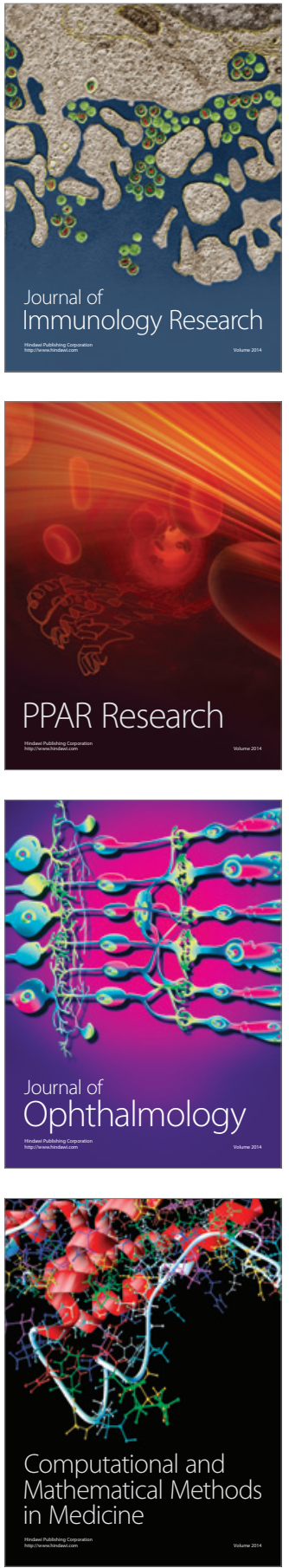

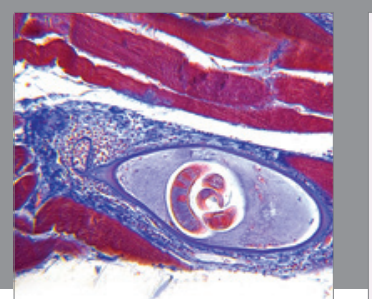

Gastroenterology Research and Practice

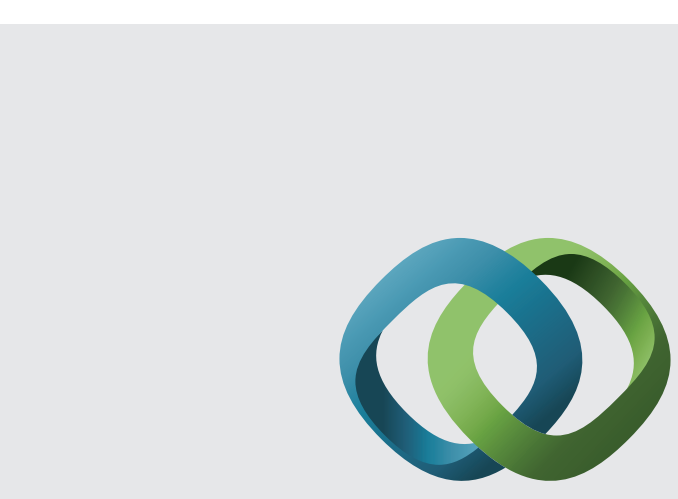

\section{Hindawi}

Submit your manuscripts at

http://www.hindawi.com
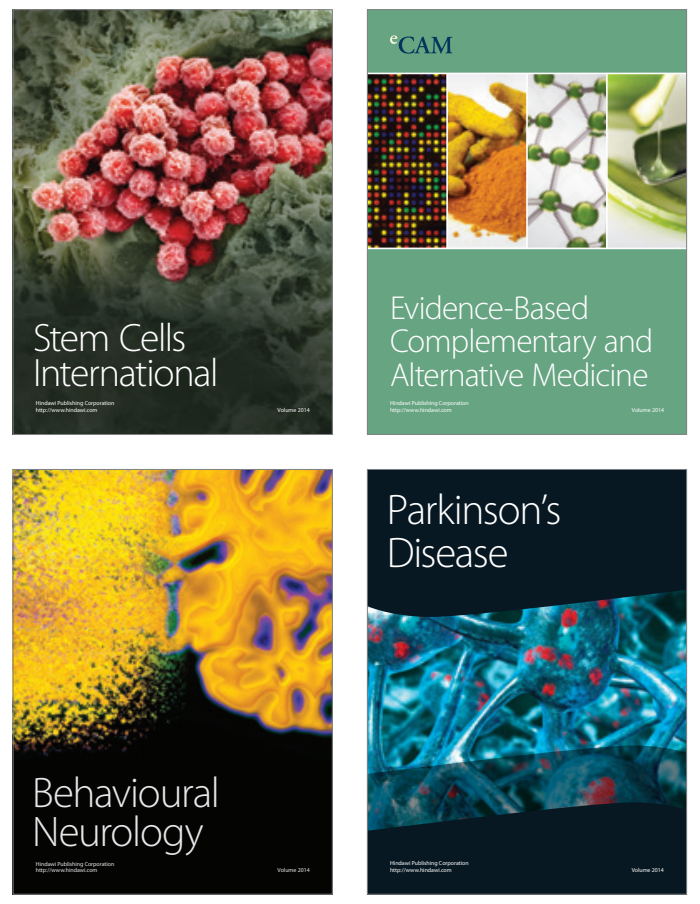
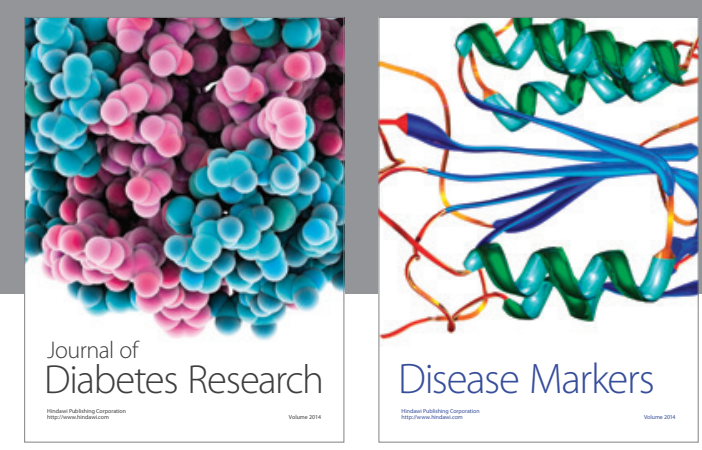

Disease Markers
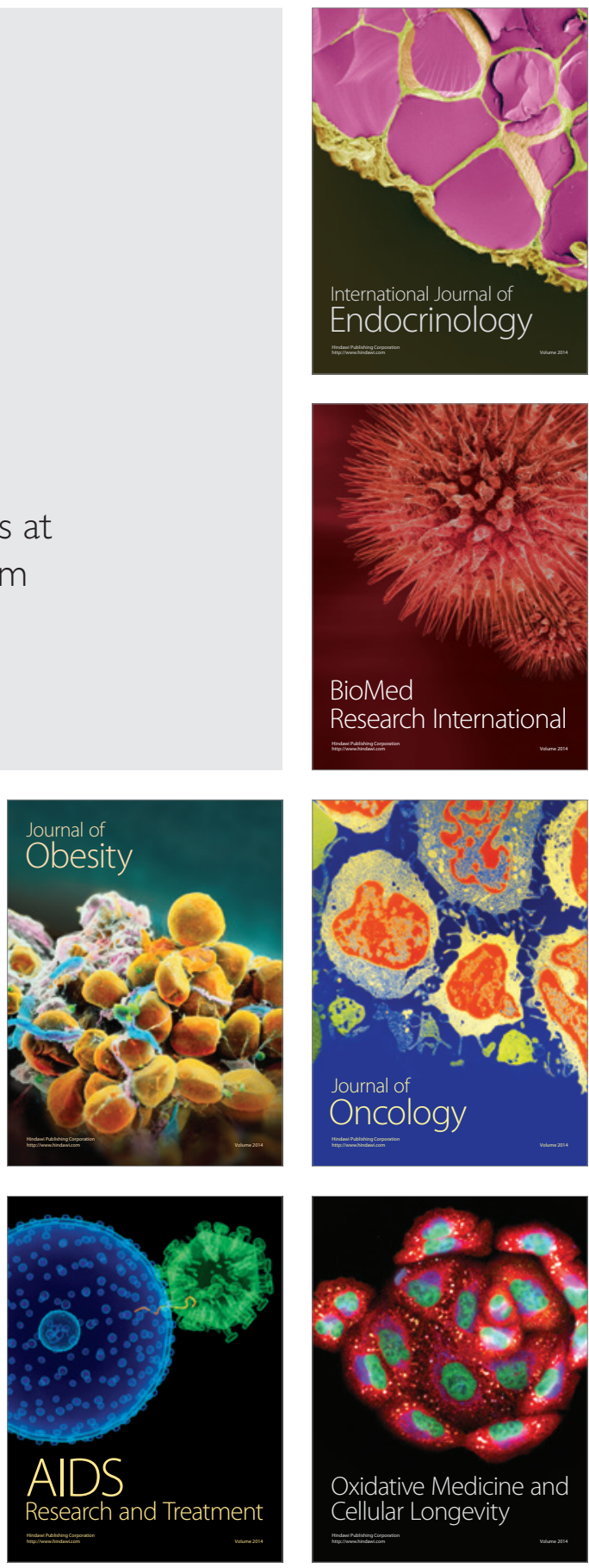